\title{
Biophilic Design (Criteria and Procedures) on the Existed Hospitals
}

\author{
Ahmed I Hassanin ${ }^{1 *}$ and Sara G Abo-Sabaa ${ }^{2}$ \\ ${ }^{1}$ Department of Construction Engineering, Egypt \\ ${ }^{2}$ Department of Architecture Engineering, Egypt \\ *Corresponding author: Ahmed I Hassanin, Department of Construction Engineering, Egypt
}

Submission: 眥 February 13, 2018; Published: 眥 March 19, 2018

\section{Opinion}

Emotions reflected the quality of relationship of humans, thought, culture, and health that every individual or society expresses. Now, the built space has been conceived and designed by giving nature a role that is not only marginal, but also irrelevant to the health and happiness individuals.

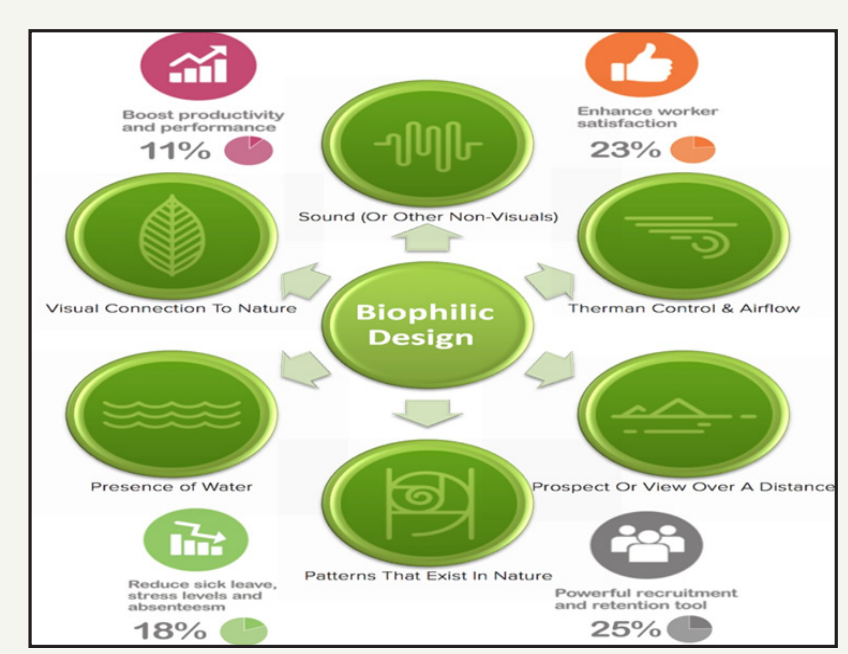

Figure 1 : Biophilic design main topics and tasks.

The main topic of this article is to shed light on the increased importance of a cultural change in the design of spaces aimed at reconnecting individuals with the patterns and processes of nature, both in the urban areas and, particularly, in hospitals. This study introduces new criteria for an architectural language for hospitals and to show the key features of health-inducing buildings.

The general concept of biophilic configuration was really conceived from the developing mindfulness that the brain and the human body create inside a "sensorially rich world" that is key to individuals' well being and scholarly, passionate and profound prosperity (Figure 1).

Mankind develops through versatile reactions to regular conditions and common jolts, for example, daylight, plants, creatures, water and scenes. In reasonableness, the period of innovation has encouraged the conviction that people can disregard their relationship with nature and that advance can be estimated with the capacity to change the regular world. The beneficial outcomes on the wellbeing and execution of people in light of biophilic plan of the fabricated condition have been checked by broad logical examinations in various settings: human services offices, work environments, youngsters' spaces, group spaces, and so forth. The reflection on the standards of biophilic configuration is especially fascinating when it is connected to human services offices. This isn't just because of the high rate of basic and stress factors in doctor's facilities for patients, their families and additionally medicinal services experts, yet additionally in light of the fact that the healing center and the city are two isolated yet interconnected frameworks, which are gone by and utilized by similar people. This relationship is portrayed by a specific exceptionality that is decisively because of the disengagement of the healing center structure, which is fundamental to empower the therapeutic practice.

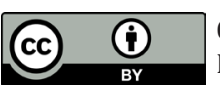

Creative Commons Attribution 4.0 International License

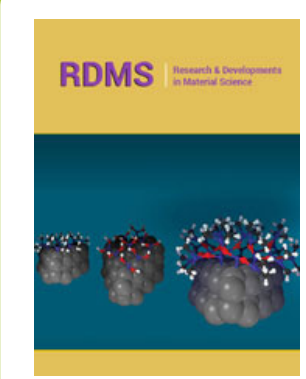

\section{Research \& Development in Material Science}

\section{Benefits of Publishing with us}

- High-level peer review and editorial services

- Freely accessible online immediately upon publication

- Authors retain the copyright to their work

- Licensing it under a Creative Commons license

- Visibility through different online platforms 